\title{
O irrepetível na fotografia e as múltiplas leituras da imagem
}

\section{The unrepeatable in photography and the multiple readings of an image}

\author{
André Leandro Silva ${ }^{1}$
}

\begin{abstract}
Resumo
Este artigo realiza um percurso por imagens fotográficas, nelas identificando os diferentes modos de perceber e compreender seu conteúdo e significado. Promove também uma reflexão acerca das revoluções que a fotografia protagonizou desde sua origem, e discute, por meio de uma análise de natureza semiótica, a forma como as categorias de primeiridade, secundidade e terceiridade de C. S. Peirce oferecem sólidas pistas no sentido de determinar o que uma imagem projeta para além do que é observado.
\end{abstract}

Palavras-chave: Fotografia. Leitura de imagens. Instante decisivo. Semiótica.

\begin{abstract}
This paper goes through photographic images, identifying in these images the diversified ways of perceiving and understanding their content and meaning. It also promotes a reflection about the revolutions photography promoted since its origin and discusses, through an analysis of semiotic nature, how C. S. Peirce's categories of firstness, secondness and thirdness offer solid clues in order to determine what an image projects beyond what is seen.
\end{abstract}

Keywords: Photography. Image reading. Decisive moment. Semiotics.

\section{Introdução}

Antes da fotografia havia a escuridão! Havia uma escuridão na memória coletiva, onde as recordações do passado eram transmitidas de geração em geração nas histórias e contos. Os acontecimentos eram noticiados por meio do boca a boca, e essas informações nem sempre eram fiéis ao evento original. Não havia a confirmação do fato por meio da imagem capturada no exato momento do acontecimento. Não havia a captura do chamado "momento decisivo" nem sua reprodução em massa apresentando os fatos a quem quisesse conferir.
Não se tratava de uma escuridão absoluta, mas de uma penumbra um pouco turva da realidade, pois sua nitidez dependia da habilidade de quem manipulava os pincéis, as tintas e outros artefatos. A pintura, o desenho, a gravura e todas as outras técnicas manuais eram os únicos meios de retratar a realidade, até os dias em que os processos fotográficos foram descobertos.

O objetivo deste estudo é refletir acerca da capacidade peculiar de a fotografia falar a respeito da vida, a história, a sociedade, com um mágico poder de perenizar uma fração de tempo e, ao

\footnotetext{
${ }^{1}$ Graduado em Desenho Industrial - Habilitação Programação Visual pela Universidade Estadual de Londrina (PR). Email: bimblaks@gmail.com
} 
mesmo tempo, torná-la imortal e encadeadora de pensamento, mensagem e documento, registro e estímulo. A pergunta que orienta a reflexão é assim enunciada: Que leitura oferecem as imagens examinadas e o que são capazes de evocar? A indagação vai além dessa dimensão e acrescenta o interesse de verificar modo como aquilo que está contido nas imagens pode falar a respeito do papel e da relevância da fotografia.

Como fundamentação para as análises, utilizamos as categorias fenomenológicas apresentadas por Charles Sanders Peirce, de primeiridade, secundidade e terceiridade, cuja caracterização será apresentada simultaneamente e as imagens também servirão como ilustração das definições. A contribuição buscada é no sentido de oferecer um roteiro de leitura de imagens e uma seleção temática para discussão acerca da fotografia.

\section{A Civilização do Olhar e as Revoluções da Fotografia}

A fotografia surgiu com sua linguagem atrelada à função social que a pintura desempenhava na sua época. Assim a linguagem, naquele momento, não só se utiliza da composição oriunda da pintura, como também se apresenta empenhada em representar a realidade tal qual ela é. "A fotografia é, ao mesmo tempo, uma forma de expressão e um meio de informação e comunicação a partir do real e, portanto, um documento da vida histórica." (KOSSOY, 2001, p. 131).

Ao observarmos os antigos álbuns de nossos pais e avós e aqueles da época da nossa infância, é quase instantaneamente o surgem de comentários como, "Lembra disso?", “Olha aquilo!", entre outras recordações. Podemos perceber que existem ali, nessas fotografias antigas, uma grande quantidade de informações, não só físicas, mas também sociais, emocionais e culturais.
Para Barthes (1984, p. 13) "O que a fotografia reproduz ao infinito só ocorreu uma vez: ela repete mecanicamente o que nunca mais poderá repetirse existencialmente". A fotografia não existe simplesmente com a função de imitar a realidade, mas sim de prolongar aquilo que existiu um dia. Assim, a fotografia funciona como uma memória social que é capaz de eternizar pessoas, locais, momentos que provavelmente não se repetirão.

A câmera fotográfica pode ser comparada a uma espécie de "máquina do tempo", que captura uma fração do tempo e transporta esse momento para o futuro, por meio da fotografia. Após vários anos, ainda poderemos ver essa mesma fração do tempo capturada anteriormente.

No futuro, poderemos ter uma fração do tempo de 1950 impressa em um pedaço de papel, contendo pessoas que já não vivem mais, carros que não mais existem, prédios que foram ao chão, plantas que foram substituídas por outras, e várias outra imagens daquela época. No entanto, ainda assim teremos uma fração do tempo de 1950, um centésimo de segundo inteiro (1/100), com as pessoas que lá estavam, os carros que por ali passavam, os prédios que assistiam a tudo calmamente do alto de seus pilares, as plantas que dançavam com a brisa leve de 1950. Essa fração de tempo, esse "pedaço de 1950" que durou apenas um centésimo de segundo, pôde ser guardado talvez para sempre, ou talvez somente enquanto as fibras do papel se mantiverem unidas. Após vários anos esse momento ainda existirá e poderá ser revivido na memória de quem estava presente naquele local e naquele "pedaço de 1950".

A fotografia nos serve como uma janela através do tempo. Não podemos voltar ao passado, nem mudar os acontecimentos, mas certamente quem viveu na mesma época e local da imagem revive, aquele momento. E os outros têm a oportunidade de olhar através dessa janela do tempo e aproveitar para dar uma espiada no passado e na maneira como ele era vivido. 


\section{"You Press the Button, We Do The Rest"}

Após as descobertas fotográficas e sua popularização entre os inicialmente interessados, a produção fotográfica ganhou intensidade no final do século XIX quando o antigo retratado tornou-se retratista.

A primeira grande revolução da fotografia ocorreu com a Kodak, através de sua revolucionária câmera Kodak $n^{\circ} 1$. Nessa época, os fotógrafos, profissionais com conhecimentos químicos, conhecedores dos processos de sensibilização, revelação, fixação, etc., foram substituídos por cidadãos comuns e suas câmeras portáteis, menores e mais fáceis de manipular.

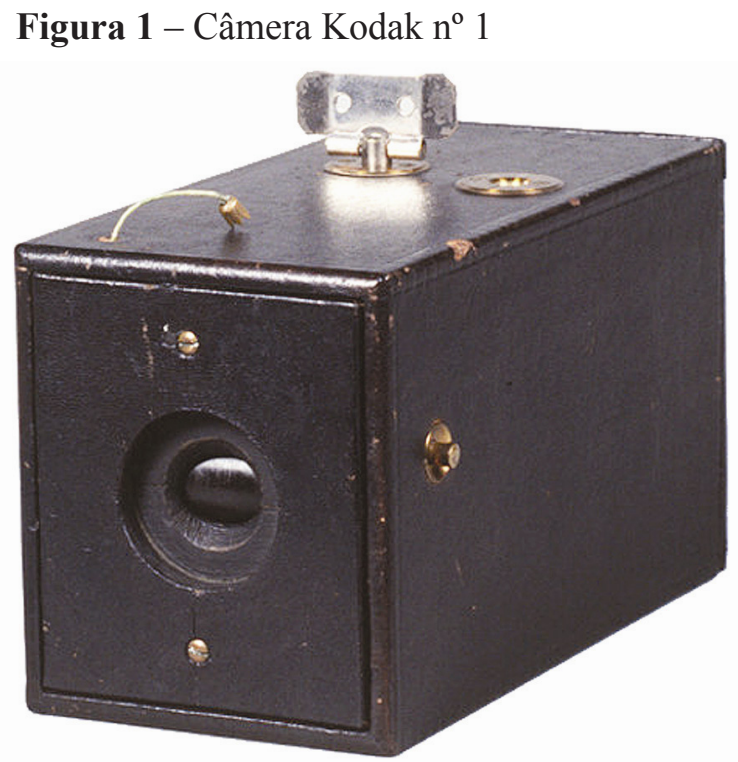

Fonte: Kodak (2010)

O então slogan da Kodak era "You press the button, we do the rest" ou "Você aperta o botão, nós fazemos o resto". Já não havia mais a preocupação com a revelação, fixação e outros processos complexos, e por meio da simplificação das câmeras esses cidadãos passaram a registrar os momentos do dia a dia, o lazer familiar, os retratos de sua família, de seus amigos, de seus animais de estimação, entre muitos outros motivos. Passaram a armazenar a história por meio das imagens. Para Kossoy (2001, p. 16), "Imagens são documentos para a história."

Jornais e revistas passaram a fazer grande uso de fotografias em suas páginas, iniciando uma era em que começaram a surgir as imagens encomendadas dos fatos da história. Nesse momento podemos perceber o nascimento do fotojornalismo. A fotografia passou a ser multiplicada pela imprensa, tornando-se portadora da informação. O texto não era mais a única fonte de informação, pois as imagens contavam muito por si sós, e as reportagens passaram a ser formadas pelo duo: texto e imagem.

Outra revolução da fotografia ocorreu a partir do momento em que pudemos obter imagens coloridas. Momentos do passado, momentos da história puderam ser guardados para sempre do mesmo modo em que haviam sido vividos, em cores vibrantes. Nas décadas seguintes, a utilização da fotografia aumentou de maneira espantosa e as imagens passaram a ser utilizadas para os mais diversos fins. "Fotografias são onipresentes: coladas em álbuns, reproduzidas em jornais, expostas em vitrines, paredes de escritórios, afixadas contra muros sob forma de cartazes, impressas em livros, latas de conservas, camisetas." (FLUSSER, 1985, p. 22)

Passamos a confiar em apenas um único sentido: a visão. Esse fato supervalorizou a imagem, e o resultado dessa cultura foi a hipertrofia da visão em detrimento dos outros sentidos. Recebemos diariamente uma grande quantidade de informações e imagens, uma saturação de elementos visuais para onde quer que miremos nosso olhar. É o ponto alto (talvez alto demais) da civilização do olhar.

\section{Click, Click, Click, Click, Click...}

Outra grande revolução da fotografia ocorreu a partir da substituição das nossas saudosas câmeras de filme pelas câmeras digitais. No início, como em muitos outros processos de transição tecnológica, houve certa apreensão, certa cautela em relação às câmeras digitais, talvez devido ao seu alto custo e à baixa qualidade de seus resultados. 
Com a evolução da tecnologia, a qualidade das imagens melhorou, os preços abaixaram e as câmeras digitais se popularizaram de forma espantosa. Junto a essa revolução digital, vem ocorrendo a banalização da fotografia, pois todos se tornaram "fotógrafos" somente por portarem uma câmera. Hoje em dia, podemos observar esses "fotógrafos" disparando suas câmeras como se fossem armas carregadas de munição infindável.

Click, click, click, click, click... Disparam incessantemente sem ao menos parar e olhar o que está sendo fotografado. Primeiro apertam o botão e depois olham no visor para conferir o que foi registrado. Muitas imagens são vistas apenas no visor da câmera, logo após o momento do click, para posteriormente serem apagadas da memória, da câmera e do indivíduo, sem nem ao menos serem descarregadas ou impressas.

\section{Imagem Fotográfica, Um Campo De Infinitas Leituras}

Partindo do pressuposto de que uma imagem é uma configuração visual destinada a produzir sentido, faremos uma leitura analítica da imagem a seguir. Com essa leitura, percorreremos as categorias fenomenológicas da semiótica de Charles Peirce, com os elementos denominados primeiridade, secundidade, terceiridade.

Figura 2 - Fileira de tanques, de Stuart Franklin/Magnum, 1989.

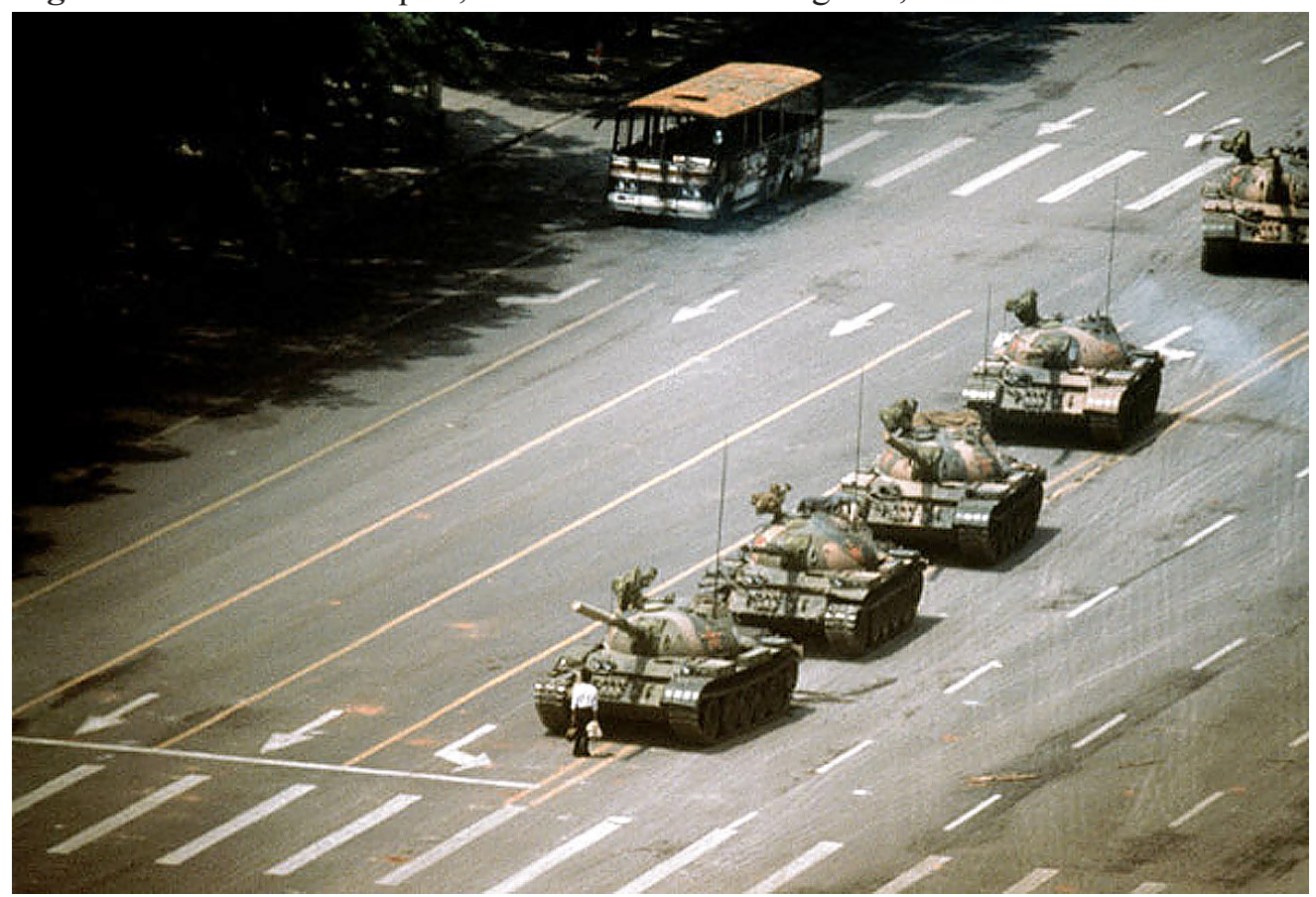

Foto: Stuart Franklin/MAGNUM

Fonte: THE STORY... (1989). 


\section{Primeiridade}

Ao dirigir nossa visão para a Figura 1, num momento inicial a relação que obtemos é a de contemplação, desprovida de referências. Percorrendo a imagem, observa-se apenas a sua essência, pois neste momento não se constitui nenhuma ligação entre a imagem apresentada e outras referências. Sentem-se apenas as cores, formas e sensações, mas ainda não se dá conta de que estas são cores, formas ou sensações. Temos apenas um sentimento vago, indiscernível, aberto a interpretação junto com seu suporte. Existe a presença da imagem levada diretamente à consciência, sem uma consciência propriamente dita. É um mundo do pensamento, porém, sem a mediação de outro nível de signos. Este é um estado de Primeiridade. Primeiridade é “[...] a primeira apreensão das coisas, que para nós aparecem [...]" (SANTAELLA, 2005, p. 46).

Segundo Peirce (2003, p. 49) a Primeiridade, ou Primeiro Correlato é "considerado como de natureza mais simples, sendo uma mera possibilidade se um dos três for dessa natureza e não sendo uma lei a menos que todos os três sejam dessa natureza."

\section{Secundidade}

Passado um primeiro momento, a imagem passa a causar certas reações ao observador. Ele passa a perceber e entender suas formas, retas, curvas, suas cores, luzes e sombras, dissolvendo o estado contemplativo. Ocorre, a partir desse momento, uma ação e reação, uma relação entre um fenômeno primeiro e um segundo fenômeno qualquer. Esse é o estado de Secundidade. Secundidade, ou Segundo Correlato

[...] é, dos três, aquele que é considerado como de complexidade média, de tal modo que se dois quaisquer forem da mesma natureza, sendo ou meras possibilidades ou existências reais ou leis, então o Segundo correlato é dessa mesma natureza, enquanto que se os três forem de naturezas diferentes, o Segundo Correlato será uma existência real. (PEIRCE, 2003, p. 50)
Ao regressarmos nosso olhar para a Figura 1, podemos observar uma superfície de formato retangular, horizontal, com linhas e elementos que se salientam no sentido diagonal. Observamos o contraste entre o centro da imagem, claro, e o canto superior esquerdo, escuro. Percebemos a luminosidade centralizada na imagem, os jogos de luz e sombra. Observamos também a frequência de um tom esverdeado que prevalece por toda a imagem, com pormenores em branco e alaranjado e um tom escuro predominante na parte superior da imagem.

Ao explorarmos a imagem, observamos uma larga avenida asfaltada, com dez pistas paralelas (visualizamos somente dez pistas devido ao corte da imagem), destinadas ao trânsito de veículos comuns como carros, ônibus e motocicletas e sinalizadas por faixas alaranjadas e brancas, contínuas e tracejadas, setas indicativas de sentido de tráfego e faixas para travessia de pedestres. Essas pistas atravessam toda a imagem, do canto superior direito ao canto inferior esquerdo, conferindo um movimento oblíquo à imagem, no sentido cruzado ao sentido de leitura ocidental (da esquerda para a direita e de cima para baixo).

Percebemos a textura da rua e a variação da espessura das linhas que atravessam a imagem e delimitam cada pista. Seis dessas pistas correm em um sentido e as demais correm no sentido contrário. Essas linhas e tracejados criam um efeito de perspectiva e profundidade na imagem.

Podemos observar dois planos nessa imagem. No primeiro plano temos um cidadão de calça preta, camisa branca, uma sacola em cada mão, parado exatamente sobre a faixa que, provavelmente, divide a avenida ao meio. Aapenas dois passos desse cidadão há um tanque de guerra, parado de frente para ele, aguardando que o homem saia do seu caminho. É possível contar três tanques enfileirados logo atrás do primeiro e um quinto tanque se aproximando. No segundo plano verificamos um ônibus parado sobre a segunda pista, abandonado e incendiado. 


\section{Terceiridade}

Após as reações causadas pela Secundidade, o observador aciona o pensamento e busca outros parâmetros: deve refletir e fazer associações para que seja gerado conhecimento. Essa é a Terceiridade, quando o observador desperta para a aprendizagem. A Terceiridade corresponde a um nível simbólico, em que passamos a representar e interpretar os eventos. Não é um caráter passivo, mas a união deste com o segundo, que adiciona um fator cognitivo, relaciona um fenômeno a um terceiro termo, e, assim, origina a representação.

A Terceiridade "aproxima o primeiro e o segundo numa síntese intelectual, pois corresponde à camada de inteligibilidade, ou pensamento em signos, através da qual representamos e interpretamos o mundo." (SANTAELLA, 2005, p. 51). Para Peirce (2003, p. 49), a Terceiridade, ou Terceiro Correlato "é, dos três, aquele que é considerado como o de natureza mais complexa, sendo lei se qualquer dos três for uma lei e não sendo mera possibilidade a menos que todos os três sejam dessa natureza."

Retornando à imagem apresentada anteriormente, percebemos que era um dia ensolarado e por meio das sombras podemos concluir que o horário era próximo ao meio-dia. Percebemos a presença de árvores na lateral da avenida, por meio de suas sombras projetadas no asfalto. Podemos afirmar que estavam na primavera ou verão, pois percebemos pelas sombras que as árvores estavam cheias de folhas.

Essa imagem apresenta um confronto entre homem e máquina, entre a fragilidade e o poder. Apresenta uma situação de conflito, de resistência, de coragem, na qual um pequeno homem se tornou um gigante, perante uma fileira de grandes máquinas de guerra. Expõe a tirania de governos autoritários nos quais o poder e a força submetem os cidadãos. A imagem em questão cumpre uma função documental, jornalística. Ela testemunha e registra um momento ímpar da história, para sempre. Tem o caráter jornalístico da captura do momento e de levar a público tal informação, de servir de meio de transporte dessa informação, de divulgar o fato, seja por meio de jornais, revistas, televisão, internet, entre outros meios de comunicação, informando e denunciando essa situação.

Podemos observar, na imagem, um ângulo de visão superior, que nos diz que ela foi produzida, provavelmente, a partir da janela ou da sacada de um prédio. Esse prédio não era muito próximo ao local onde ocorreram os fatos, pois podemos perceber um ângulo fechado e um aplainamento da imagem, devido ao uso de uma teleobjetiva de grande alcance, reduzindo também a sensação de tridimensionalidade dos elementos.

Percebemos que todos os elementos da imagem estão focados, o que é resultado da utilização de uma abertura pequena de diafragma, a qual valorizando a imagem como um todo e confere a ela, maior profundidade de campo. Outra substância de expressão que podemos notar é a escolha por um tempo de exposição rápido, por meio de uma alta velocidade de obturador, congelando o "momento decisivo" que se fez presente (o fotógrafo não arriscaria borrar a imagem ou até mesmo perder o momento, devido à escolha de uma velocidade lenta).

Temos em realce na imagem, o homem e a fileira de tanques, que forma uma barreira ao sentido do nosso olhar e relaciona-se aos demais elementos da imagem por meio da disposição oblíqua e sua organização. Podemos perceber, nessa imagem, a captura do "momento decisivo" descrito pelo fotógrafo francês Henri Cartier-Bresson, francoatirador da arte fotográfica que utilizava, com maestria, sua Leica em busca do instante fugaz em que uma imagem se forma por completo em frente à câmera (ASSOULINE, 2008). 


\section{O "Momento Decisivo"}

Para compreender melhor o "momento decisivo" imaginemos uma fotografia feita em um local onde podemos perceber que ainda está escuro, por volta das 6 horas da manhã. Nessa fotografia, podemos ver uma avenida de uma cidade chinesa, próxima a uma praça. Devido ao horário, essa avenida está aparentemente calma, vazia, sem nenhuma pessoa por perto, nenhum carro, nenhuma criança, nenhuma manifestação, nenhum estudante, nenhum tanque de guerra. Era junho de 1989. Após 5 horas e 49 minutos dessa fotografia imaginária ser feita, nesse mesmo local, um estudante, sozinho, fez uma fileira de tanques chineses ficar imóvel. Os tanques pararam, as pessoas pararam, as câmeras pararam, apontadas para uma única direção. $\mathrm{O}$ mundo parou, para assistir à coragem de um pequeno homem que se tornara um gigante perante uma fileira de grandes máquinas sem vida e sem coração.

Nesse exato momento, Stuart Franklin, de uma sacada do quinto andar do Hotel Beijing, hotel reservado à imprensa, exatamente 5 horas e 49 minutos após o registro da fotografia que imaginamos, teve a sorte de ter nas mãos o "momento decisivo", e esta imagem entrou para a história como uma das 100 fotografias mais importantes do século XX. Apesar do primeiro momento imaginário provavelmente ter acontecido, a primeira fotografia que imaginamos é uma imagem fictícia, que nunca existiu, pois não havia nenhum "momento decisivo" para ser registrado.

A imagem apresentada revela o poder dos tanques de guerra e ao mesmo tempo a sensibilidade dos seus condutores, ao pararem suas máquinas perante o pequeno homem no meio da rua. Revela a fragilidade do pequeno homem, solitário e indefeso, de sacola na mão, e ao mesmo tempo a sua coragem e poder para tornar imóvel uma fileira de grandes máquinas de destruição. Esta imagem apontou novos caminhos, por meio dos o cidadão frágil e solitário deixou de temer e aceitar tudo o que lhe era imposto e passou a se encorajar e lutar pelo que acreditava ser certo.

Imaginemos agora outra fotografia. Nessa imagem podemos ver uma estrada que leva a um vilarejo. Uma estrada ladeada por uma vegetação rasteira, e algumas árvores em segundo plano. Nessa estrada não há nenhuma pessoa, nenhuma carroça, nenhuma criança e nenhum soldado. Era junho de 1972.

Exatamente 2 horas e 37 minutos após esta fotografia imaginária ser tirada, essa mesma aldeia é bombardeada por aviões que lançam sobre ela quatro bombas de Napalm. Jovens e adultos, crianças e idosos, fogem correndo em desespero enquanto eram consumidos pela química do Napalm. Uma garota corre gritando "Nóng Quá!" (Muito quente!), enquanto seu vestido é devorado pelas chamas. Ela corre desejando apenas não estar ali, corre e cai desmaiada nos braços de Nick Ut, fotógrafo da agência Associated Press.. Um registro histórico.

Nick não pensou duas vezes ao sacar sua câmera e registrar o "momento decisivo" que ali se apresentava. Ganhou o prêmio Pulitzer com essa imagem e se tornou-se o autor de uma das mais conhecidas e importantes imagens do século. Como apresentado no exemplo anterior, a primeira fotografia nunca foi registrada, embora o momento provavelmente tenha existido. 
Figura 3 - Crianças fugindo de bombardeio Nick Ut, 1972.

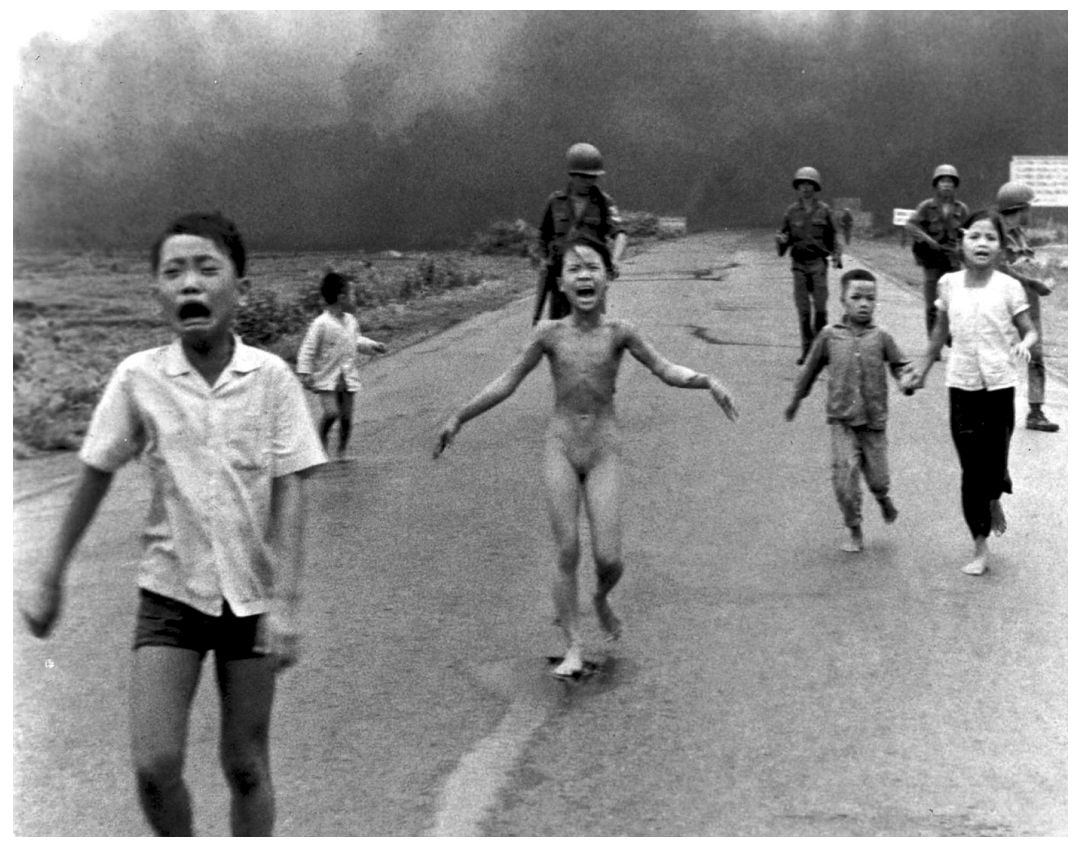

Fonte: NO CAPITION... (2007).

Essas imagens retratam momentos decisivos, não somente com base na visão de Bresson, na questão técnica da fotografia, do click no momento exato, mas também retratam momentos decisivos na história da Humanidade, por meio das quais importantes decisões foram tomadas, opiniões foram formadas e a própria história foi afetada. Essas imagens, por meio dos seus signos, têm extrema relevância e possuem o seu lugar reservado na história da fotografia.

\section{Os Signos}

Os signos podem relacionar-se com o objeto por meio da similaridade, por correlação espaçotemporal ou por meio de um hábito ou convenção. Signo é algo que representa alguma coisa para alguém. (PEIRCE, 2000, p. 46). Há classificações para os signos, sendo a classificação tricotômica mais conhecida delas, aquela que descreve as relações entre os signos e seus objetos: a classificação em ícone, índice e símbolo. O representamen [...] divide-se por tricotomia em signo geral ou símbolo, índice e ícone. (PEIRCE, 1980, p. 28)

O ícone é o signo que tem relação de correspondência com o seu objeto e representa algo pelo fato de ser como é. Por exemplo, o ícone da lixeira na área de trabalho dos computadores representa uma lixeira porque é realmente a figura de uma lixeira como podemos reconhecê-la. Para Peirce (1980, p. 28), “O Ícone é um representamen que preenche essa função em virtude da característica própria que possui, mesmo que seu objeto não exista. Assim, a estátua de um centauro [...] representa um centauro $[. .$.$] exista ou não o centauro."$

O índice é o signo que tem uma relação de causa e efeito com o seu objeto. O objeto não está presente, mas percebemos indícios da sua presença, resultando em uma relação de causalidade. Por exemplo, pegadas na lama nos dá indícios de que alguém passou por ali. De acordo com Peirce (1980, p. 28), "Índice é representamen em virtude de uma característica que deve à existência de seu objeto, e que continuará tendo quer seja interpretado como 
representamen ou não. Por exemplo, um antiquado higrômetro é um índice."

O símbolo é o signo em que o objeto representado e a sua representação têm uma relação baseada em um hábito ou convenção. O símbolo não apresenta similaridade com o seu objeto, mas relações do tipo causa-consequência. Para Peirce (1980, p. 28), "Símbolo é um representamen que preenche sua função sem qualquer similaridade ou analogia com seu objeto e é igualmente independentemente de qualquer ligação factual, símbolo unicamente por ser interpretado como reresentamen. Por exemplo, uma palavra genérica, uma sentença, um livro."

Figura 4 - Proibido Fumar.

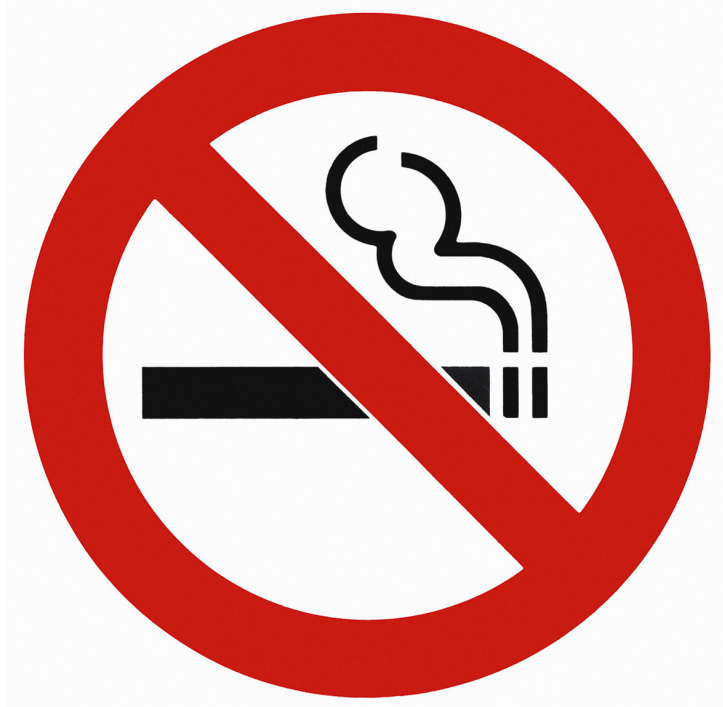

Fonte: Google Imagens.

Observando a Figura 4, podemos perceber um ícone na figura do cigarro, aceso, exalando fumaça, pois esse desenho é a própria representação (estilizada) de um cigarro, tal como podemos reconhecê-lo. Temos ali o próprio objeto representado. Mas também podemos reconhecer um símbolo, ao analisar o círculo vermelho que rodeia e delimita a imagem e a faixa transversal, também vermelha, que parte deste círculo, no quadrante superior esquerdo, atravessando o ícone do cigarro, para encontrar-se novamente com o círculo no quadrante inferior direito.
E esse conjunto círculo/faixa, pode ser tratado como símbolo, devido ao tipo de relação que ele tem com o objeto ao qual ele representa. Nesse caso, ele não representa algo físico, material, palpável, mas uma convenção, uma lei, incorporada à mente do observador e que tem o significado de proibição. Enquanto o ícone do cigarro representa o próprio cigarro, o círculo de contenção e a faixa transversal representam uma convenção, uma lei de proibição. E o conjunto nos transmite a mensagem: É PROIBIDO FUMAR. Essa é uma convenção mundial e na maioria dos países esse símbolo pode ser lido e compreendido.

Agora imaginemos uma placa com esse mesmo símbolo, cravada no centro de uma aldeia indígena, isolada, sem acesso à televisores, internet, rádio ou qualquer outro meio de comunicação com a civilização moderna. Para os habitantes dessa aldeia, a imagem representada nessa placa não significa muita coisa. Não há símbolo, pois os observadores não reconhecem a imagem representada na placa como um aviso, uma ordem, uma lei de proibição. Isso ocorre porque esse signo necessita de um terceiro elemento para se tornar símbolo de fato: de uma mente observadora, e com as devidas referências para que a ligação entre o signo e o seu objeto sejam concretizadas. Portanto, podemos dizer que o símbolo depende não somente de uma convenção, ou lei, mas requer também um interpretante, ou seja, a mente do observador, a qual, por meio de referenciais preestabelecidas, validará ou não esse elemento como símbolo. Estabelecemos então a relação: SÍMBOLO OBJETO - INTERPRETANTE.

Retornemos à Figura 2 apresentada na página 6 desse trabalho. Observando somente a imagem, podemos identificar alguns signos de diferentes classes. Nessa imagem, a figura do ônibus incendiado, somado à fileira de tanques de guerra constituem um índice, pois esses elementos nos apresentam indícios de um conflito, que não nos é revelado por completo pela imagem. Já os signos pintados na rua: setas, linhas, faixas, constituem 
símbolos, pois poderiam ser apenas elementos decorativos mas, devido à algumas convenções, tornaram-se símbolos, representando determinadas leis de trânsito, como por exemplo: "vire a direita", "siga em frente", etc.

A fotografia desse rapaz, parado em frente aos tanques de guerra, tornou-se um ícone, ao representar o próprio rapaz que esteve nesse local, os tanques, o conflito ocorrido nesse dia. Essa mesma fotografia, tornou-se um símbolo, da própria luta contra a tirania, símbolo do inconformismo, da resistência e de toda a coragem que esse rapaz teve quando, surpreendentemente decidiu enfrentar, não somente os tanques, como objetos, como armas de guerra, mas também como símbolos, de todo o poder de um governo tirano, opressor e impiedoso.

Na Figura 3, percebemos a imagem dos soldados e crianças como ícones, representando os próprios homens e crianças que estiveram nesse local, no "momento decisivo" registrado nessa fotografia. Essa mesma fotografia nos mostra os seguintes signos: soldados fardados, armados e de capacete, somada à fumaça negra que pode ser vista ao fundo e à figura de uma menina correndo nua, de braços abertos no centro da imagem, fugindo do caos instalado no que costumava ser o pacato vilarejo onde vivia. E esses signos são apresentados como índices, apresentando-nos os indícios de uma guerra. A figura da menina chama a atenção também por nos remeter a um dos mais conhecidos símbolos cristãos: a cruz, que na cultura cristã simboliza o sacrifício.

\section{Considerações Finais}

Percebemos que ao observar uma imagem passamos por três estágios de consciência, onde contemplamos a imagem, isentos de qualquer referência, passamos por um momento onde reagimos às informações que a imagem nos apresenta, começamos a perceber e entender os seus elementos, observamos os seus signos e partimos para o entendimento do que eles representam.
Os ícones apresentados na imagem se lançam ao olhar, identificando o que ocorreu naquele local. Assim deciframos os indícios acerca do que mais possa ter ocorrido além do que a imagem nos apresenta, e então buscamos outros parâmetros, outros referenciais, passamos então a fazer associações a fim de criar representação e interpretação a respeito do que está sendo observado e criar ligações com o que esses elementos nos simbolizam.

\section{Referências}

ASSOULINE, Pierre. Cartier-Bresson: o olhar do século. Porto Alegre: L\&PM, 2008.

BARTHES, Roland. A câmara clara: nota sobre a fotografia. 2. ed. Rio de Janeiro: Nova Fronteira, 1984.

FLUSSER, Vilém. Filosofia da caixa preta. São Paulo: Hucitec, 1985.

KODAK. Disponível em:<http://www.kodak.com>. Acesso em: 4 abr. 2010

KOSSOY, Boris. Fotografia \& história. 2. ed. São Paulo: Ateliê, 2001.

NO CAPITION Needed. Nick Ut. 2007. Disponível em: <http://www.nocaptionneeded.com>. Acesso em: 8 abr. 2010.

PEIRCE, Charles Sanders. Semiótica. 3. ed. São Paulo: Perspectiva, 2000. . Semiótica. São Paulo: Perspectiva, 2003. . Terceiridade degenerada. In: PEIRCE, Charles Sanders. Conferências sobre o pragmatismo: as categorias. São Paulo: Abril Cultural, 1980.

SANTAELLA, Lúcia. O que é semiótica. São Paulo: Brasiliense, 2005.

THE STORY Behind the Tank Man of Tiananmen. 1989. Disponível em: <http://portfoliography.com>. Acesso em: 3 jul. 2010.

Recebido em: junho de 2010 Aceito em: setembro de 2010 